\title{
Hydrological Disturbances of the Caloosahatchee River and Everglades Environmental Science
}

\author{
Ayush Madhar
}

\begin{abstract}
Hydrological Disturbances of the Caloosahatchee River and everglades will be investigated in relation to how the rivers themselves are affected by nitrogen in the soil and how the wildlife in the areas not including the effect of human interaction. This is a very important topic in the field because recently the everglades and Caloosahatchee river have been having many issues with water quality and reduction in wildlife. I am interested in this since it is a local issue and will have a large impact on me whether that is economically affecting the state or just reduction of food and drinking water quality. Furthermore, biology and sciences have always interested me, and I have actually volunteered at the Caloosahatchee nature reserve so I would like to gain more information and spread it so other people can take action to help solve these problems. While the awareness of this problem is becoming more and more widespread, and people are beginning to take action to reduce it there is still more action that needs to be taken. This review will not explore the threat that invasive species pose to the Caloosahatchee River and everglades.
\end{abstract}

Index Terms - Hydrological Disturbances, Everglades Environmental Science.

\section{INTRODUCTION}

Hydrological Disturbances are factors that interfere with bodies of water and their ecosystems. A large hydrological disturbance that has affected the Caloosahatchee river is red tide. The water samples of the river were collected to investigate nutrient concentrations and phytoplankton community using chromatography (liquid chromatography) along with measurements of temperature and salinity (concentration of salts). The water was relatively warm and had a low chlorophyll fluorescence in the lower water regions, but this increased towards the middle and decreased new the mouth of the river. The salinity signature moved up the river mouth and chlorophyll were more like coastal marine waters with higher or increasing temperatures during the dry season. The higher levels of salinity in conjunction with high levels of nitrogen from runoff fertilizer are what would cause the red tide. Other hydrological disturbances include natural disasters like hurricane Charlie which overall lowered the salinity and brought heavy rains. This caused the transport of nutrients to parts of rivers affecting some wildlife like phytoplankton.

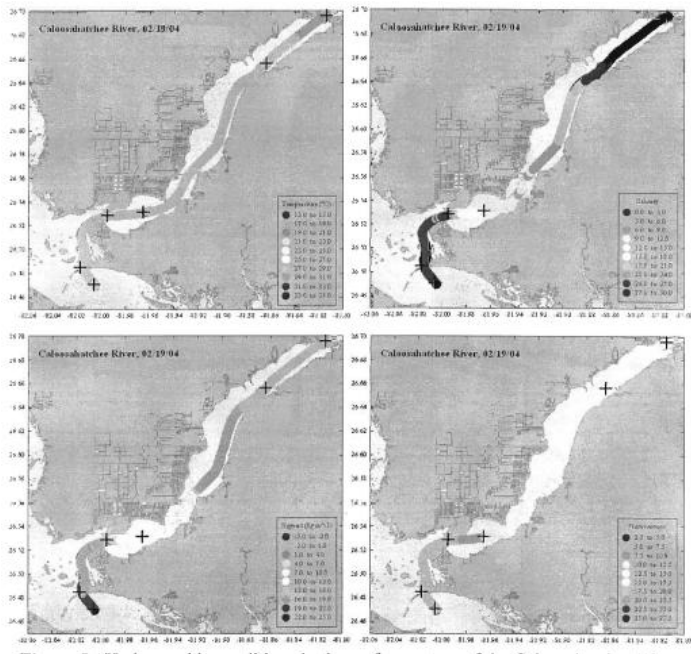

Figure 1 (1) Represents

An issue with this study is that it is a very old study that uses data from around 2003-2004 and in some cases even earlier. Furthermore, this study has high ecological validity due to the fact that the data was collected directly from and at the river leading to more accurate results and a better representation of what would actually happen.

Furthermore, the everglades have also had various hydrologic disturbances that occur. First off the everglades was drained of its water which caused the death of many water animals and vegetation due to reduced water ranging from around 1 to -2 feet below ground level which before the drain were around 3 to -1 feet. Also, the elevation of the wetlands themselves where altered by these drainages and droughts since "the balance between peat accretion and peat Oxidation" (2) was changed. The survival and effectiveness of some invasive vegetation and animals may be increased. In addition, these hydrological disturbances have affected habitats in the Everglades. It was mentioned that "Nesting and foraging by Snail Kites and endangered Cape Sable Seaside sparrows have conflicting hydrologic requirements that call for different habitats and marsh elevations" leading to the Kites having a more difficult time surviving. This study also had high ecological validity since the observations were done directly at the everglades. Also, this study used data from a large period of time, so it isn't necessarily up to date, but it is still an issue that is slowly getting resolved.

In addition to this often times large amounts of water are drained from the everglades to be used for agriculture and other such purposes which altered the water levels as well as causing a decline in the ecosystem and its animal diversity. Also, the "Polluted agricultural and urban runoff leads to excessive inputs of nutrients, such as nitrogen and phosphorous, and causes imbalances in the water chemistry" 
(3) which is the main cause of algae blooms. There are various sights and stations which are used in order to monitor these waters and the lengths of the everglades. Any small or large change can end up having a significant impact. For example, "Larger-scale changes followed as canals, levees, pumps, and storage structures were built in attempts to control flooding, increase available dry land, and provide water for agriculture and the growing population (Light and Dineen, 1994; McVoy et al., 2011)" which led to many new regulations that had to be made including flood control and to the destruction of many land habitats. So not only the lack of water but also the abundance of it in earlier times can lead to hydrological disturbances

All in all, both the Everglades and the Caloosahatchee have various hydrological disturbances that range from red tide (algae blooms) to invasive species (Burmese pythons). Nitrogen from things like fertilizer goes into the Caloosahatchee River and is what causes the Red tide which is a process known as eutrophication. When this occurs, it forms a layer of algae on the surface of the water which decreases the amount of sunlight that reaches the bottom causing plants to die which will kick off a chain killing other fish and animals negatively affecting the river's biodiversity. The main thing that affects the biodiversity in the everglades is invasive species. There are many invasive species such as the Burmese python and Snail Kites which dominate in the new environment (everglades) and kill off many of the native animals that already live there. So hydrological disturbances other than human interaction play a large role and negatively affect the Ecosystems created by the Everglades and the Caloosahatchee River.

\section{REFERENCES}

[1] Caloosahatchee river and estuary.pdf (usf.edu)

[2] 11_chpt2.pdf (sfwmd.gov

[3] http://www.landscope.org/florida/threats/hydrologic_disturbances/

[4] https://www.frontiersin.org/articles/10.3389/fenvs.2020.00003/full 